\title{
PERSPECTIVAS DE LA VIOLENCIA DE GÉNERO EN LA ERA DE LA TEORÍA NEOCONSTITUCIONAL COMO EL NUEVO PARADIGMA DEL DERECHO INTERNACIONAL DE LOS DERECHOS HUMANOS
}

\author{
PERSPECTIVES OF GENDER VIOLENCE IN THE AGE OF NEOCONSTITUTIONAL \\ THEORY AS THE NEW PARADIGM OF THE INTERNATIONAL LAW OF HUMAN \\ RIGHTS
}

\author{
María Belén Redondo*
}

\begin{abstract}
RESUMEN: Los cambios en la nueva concepción del Estado Democrático de Derecho que surgen a partir de la toma de conciencia de la existencia de determinados derechos que se consideran como fundamentales por la comunidad internacional, influyen de modo directo en el diseño de políticas públicas, de creación de normas jurídicas y en el modo de resolver los casos judiciales. Es así que se presenta a la Teoría Neoconstitucional como una nueva teoría del derecho que permite integrar los derechos con sus respectivas garantías, y que se ocupa tanto de las normas como de los principios y los valores de Derechos Humanos y de su internalización en los ordenamientos de los Estados, es decir, se ocupa del fenómeno de mundialización de estos derechos. Dentro de los derechos fundamentales encontramos los que poseen las mujeres en lo que concierne a vivir una vida libre de toda violencia en la que se respete su dignidad y autonomía de la voluntad, amén de que los índices de violencia contra ellas aumentan día a día en todos los países del mundo. De este modo los Estados deberán cumplimentar con las medidas de acciones positivas tendientes a garantizar el efectivo goce de los derechos reconocidos por los Pactos internacionales de Derechos Humanos.
\end{abstract}

\begin{abstract}
The changes in the new conception of the Democratic State of Law that arise from the awareness of the existence of certain rights that are considered fundamental by the international community, have a direct influence on the design of public policies, the creation of legal norms and how to solve judicial cases. This is how the Neoconstitutional Theory is presented as a new theory of law that allows integrating rights with their respective guarantees, and that deals with both the norms and the principles and values of Human Rights and their internalization in the legal systems. of the States, that is, deals with the phenomenon of globalization of these rights. Within the fundamental rights we find those that women possess in what concerns to live a life free of all violence in which their dignity and autonomy of the will is respected, in addition to that the indices of violence against them increase every day in all the countries of the world. In this way, the States must comply with the measures of positive actions tending to guarantee the effective enjoyment of the rights recognized by the International Covenants on Human Rights.
\end{abstract}

PALABRAS CLAVE: violencia, género, derechos humanos, neoconstitucionalismo, Estados

KEYWORDS: violence, gender, human rights, neoconstitutionalism, States

Fecha de recepción: 04/04/2018

Fecha de aceptación: 05/07/2018

doi: https://doi.org/10.20318/universitas.2018.4310

* Abogada y Profesora en Derecho por la Universidad Nacional de Rosario y Universidad Abierta Interamericana, Argentina. Magister en Derecho Internacional de los Derechos Humanos, Justicia Penal Internacional y Derecho Internacional Humanitario por el Instituto Internacional de Estudios Globales para el Desarrollo Humano. Diplomada en Defensa Internacional de los Derechos Humanos por la Universidad de ZaragozaCLADH. Doctoranda en Derecho por la Facultad de Derecho de la Universidad Nacional de Rosario. E-mail: mariab-redondo@hotmail.com

Universitas, 2018, $\mathrm{N}^{\circ} 28 /$ pp. 38-58

ISSN 1698-7950 / doi: https://doi.org/10.20318/universitas.2018.4310 


\section{1.- ALGUNOS CONCEPTOS DERIVADOS DE LA INTERNALIZACIÓN DE LOS DERECHOS HUMANOS}

"del principio que establecía que los derechos humanos valen en la medida que los reconocían las leyes, se pasa a que las leyes y las demás normas jurídicas valen en la medida que respetan los contenidos esenciales de los derechos humanos"1.

Fue el Siglo XX el que marcó un nuevo proceso en la historia del mundo provocando una verdadera revolución con el "reconocimiento del individuo como sujeto de la comunidad internacional (...) que consolidó un nuevo paradigma humanista del Derecho internacional, centrado hasta ese entonces solo en los Estados y sus intereses"2.

Pero proyectándonos aún más allá, Luigi Ferrajoli nos explica que se ha producido "un cambio de paradigma "revolucionario" en tanto afecta, no sólo el papel del derecho y las condiciones de validez de las leyes, sino también el papel de la jurisdicción (afectando la relación juez-ley) el papel de la ciencia jurídica y la naturaleza de la democracia"3.

Resulta que esta explosión de reconocimiento de derechos inherentes a todos los seres humanos por su condición de tal, provocó grandes cambios en los ordenamientos jurídicos de los Estados del mundo.

Es que "La comunidad americana organizada, comprendió, a poco de su constitución, que la democracia y los derechos humanos debían ser los pilares estructurales sobre los que debían asentarse"4.

Es decir, la nueva sociedad emergente luego de la Segunda Guerra Mundial necesitaba sentar sus bases sobre una estructura democrática que se enfocara en la esencia del ser humano, y la respetara como tal.

Es de este modo que en 1948 surge el embrión del fenómeno actual de expansión de la esfera del derecho con la Declaración Americana de los Derechos y Deberes del Hombre y la Carta de la Organización de los Estados Americanos.

A partir de allí, comenzó una labor de producción de contenido acerca de los Derechos Humanos, y su consecuente especificación en diversos Tratados internacionales.

\footnotetext{
1 S. ALFONSO, "Neoconstitucionalismo", Anales de la Academia Nacional de Ciencias Morales y Políticas. Sesión Privada del Instituto de Política Constitucional, Abril de 2008, p1.

2 M. TRUCCO, Convención Americana sobre Derechos Humanos: Pacto de San José de Costa Rica, Editorial Juris, Rosario, 2017.

3 A. ALTERIO, "Corrientes del constitucionalismo contemporáneo a debate", Anuario de Filosofía y Teoría del Derecho, Mayo 2013, p. 227.

${ }^{4}$ M. TRUCCO, Convención Americana sobre Derechos Humanos: Pacto de San José de Costa Rica, cit.
} 
Este proceso, vio nacer así también, la Convención Americana de Derechos Humanos de 1969, que se constituye en un documento esencial porque reconoce la supremacía de órganos internacionales específicos que llevan adelante la interpretación de esta Convención y de este modo la Corte Interamericana fija pautas directrices a través de su jurisprudencia.

Podemos decir que entendemos por derecho internacional de los Derechos Humanos al sistema de normas, principios y valores que incluye a todos los Tratados Internacionales de Derechos Humanos, la Carta de la OEA, las Opiniones Consultivas y la jurisprudencia de la Corte Interamericana de Derechos Humanos, y aquellos instrumentos que nacen en foros o en cumbres judiciales, conforme al principio pro homine que colaboran a tutelar de un modo más amplio y efectivo los derechos de los seres humanos, como por ejemplo, las 100 Reglas de Brasilia sobre el acceso a la justicia de las personas en condición de vulnerabilidad.

La revolución que provocaron estos derechos llegó a tal punto que ha logrado derribar las estanterías de la teoría del derecho imperante en el siglo XX: el positivismo jurídico, en virtud de la cual se ha dicho que se "nos acostumbró a pensar el derecho en función de la fuerza per se que éste pueda ejercer para aplicar sus dictados, lo cual se conoce en idioma inglés como enforcement. El derecho sin fuerza coactiva, y sin capacidad de forzar a cumplir, es un derecho incompleto y débil", sin embargo, El enforcement de los procesos de defensa de derechos humanos suele romper con esa tendencia"5.

Definiendo lo que entendemos por Derechos Humanos podemos decir que hacemos alusión a ello cuando hablamos de aquellas facultades que corresponden a todos los seres humanos del mundo, por ser inherentes a su dignidad humana, que subsisten a todas las fronteras en el mundo y que no implican un reconocimiento de los Estados, sino que su fuerza radica en haber nacido con la humanidad misma.

El trabajo de los Estados será adecuar las legislaciones actuales al cumplimiento de lo dispuesto por el Derecho internacional de los Derechos Humanos, para lograr la real efectivización de los mismos.

Así también pueden definirse no sólo por su naturaleza humana, sino también conforme al rol que ocupa la persona en la sociedad, es así que surgen derechos fundamentales a proteger, tal es el caso de los derechos del trabajador, el de las personas de la tercera edad, los niños, las niñas, las mujeres, etc.

${ }^{5}$ H. RAMÍREZ GARCÍA y OTROS, Derechos Humanos, Editorial Oxford University Press, Editorial Oxford University Press, México, 2011. 
El catálogo se va ampliando con el paso del tiempo, de hecho estamos actualmente en este proceso, porque justamente los avances sociales provocan nuevos conflictos y nuevos vulnerables, y es así que el derecho se va irradiando para resolver otras problemáticas.

Asimismo otro concepto que surge relacionado con los Derechos Humanos, es el de "conciencia jurídica universal", que se constituye como fuente material última de todo el derecho, y es así que restituye "al ser humano su condición de sujeto del derecho tanto interno como internacional. Estamos ante un ordre public internacional humanizado (o verdaderamente humanista) en el que el interés público o el interés general coincide plenamente con la prevalencia de los derechos humanos, -lo que implica el reconocimiento de que los derechos humanos constituyen el fundamento básico, ellos propios, del ordenamiento jurídico"6.

La conciencia jurídica universal o la comunidad internacional deben ser entendidas como sinónimos que aparecen "en el marco donde habita con toda intensidad el consentimiento de los Estados como manifestación jurídica por excelencia de su soberanía y se plasma en el sector concerniente a los procedimientos de creación de normas internacionales"7.

Al reconocimiento de estos derechos fundamentales, se les suma otro avance, que es el de comenzar a definir cuales principios se desprenden de estos derechos, como así también se ponen de relieve los valores que se buscan proteger.

De este modo la "esfera del Derecho" -haciendo alusión con este término a las fuentes del Derecho- que debe ser tenida en cuenta por los Jueces para dictar sentencia, por el Poder Ejecutivo para establecer políticas públicas, y por el Poder Legislativo a la hora de redactar normas, se compone de: normas jurídicas internas e internacionales, principios y valores.

Los principios toman tal relevancia al punto de que Cançado Trindade ha dicho que: "Al contario de los que intentan -a mi juicio en vano- minimizarlos, entiendo que, si no hay principios, tampoco hay verdaderamente un sistema jurídico. Sin los principios, el "orden jurídico" simplemente no se realiza, y deja de existir como tal $(\ldots)^{\prime 8}$.

\footnotetext{
6 A. CANÇADO TRINDADE, "La ampliación del contenido material del ius cogens", curso derecho internacional 2007, http://www.oas.org/es/sla/ddi/docs/publicaciones_digital_XXXIV_curso_derecho_inter nacional_2007_Antonio_Augusto_Cancado_Trindade.pdf

7 F. QUISPE REMÓN, "Ius cogens en el Sistema Interamericano: su relación en el debido proceso", Revista de Derecho, Julio-Diciembre 2010.

8 A. CANÇADO TRINDADE, "La ampliación del contenido material del ius cogens", curso derecho internacional 2007,
} 
Es así que cambia la estructura del sistema jurídico que ahora se basa primordialmente en derechos más que en normas, y estas normas serán válidas en tanto y en cuanto respeten el sentido y el alcance de los Derechos Humanos que protegen.

Con lo cual en este nuevo Estado Democrático de Derecho, la internalización del derecho internacional provoca necesariamente el control de constitucionalidad y de convencionalidad, como garantías para la sociedad de que se están respetando sus derechos fundamentales.

Como proceso histórico, esta internalización encontró asidero primero en la ratificación de los Pactos internacionales de Derechos Humanos, y luego en la incorporación de los mismos a las Constituciones Nacionales de los Estados del mundo.

Así también hay que considerar que "En el dominio del Derecho Internacional de los Derechos Humanos, movido por consideraciones de ordre public internacional, estamos ante valores comunes y superiores, que le son subyacentes, y que se configuran verdaderamente fundamentales e irreductibles"9.

Pero la incorporación de los Tratados no dio por terminado el tema, por cuanto se constituyó en el puntapié para lograr una real efectivización de los derechos contemplados.

Es así como comienzan a surgir desfasajes entre el ser y el deber ser, entre la existencia de derechos legislados y los mecanismos insuficientes o no contemplados para acceder a la defensa de los derechos fundamentales.

$Y$ en consecuencia nos preguntamos ¿Es importante el rol que desempeña un Estado al declarar derechos? Sí, pero es tan importante como lo es el papel que asume un Estado en el compromiso por efectivizarlos ${ }^{10}$.

De modo que pareciera que lo legislado, de nada sirve si las personas no encuentran las vías idóneas para poder defenderse de actos que violen sus derechos fundamentales, por ello la necesidad de una teoría del derecho que promueva la especificidad no solo de los derechos sino también de sus correspondientes garantías.

http://www.oas.org/es/sla/ddi/docs/publicaciones_digital_XXXIV_curso_derecho_inter nacional_2007_Antonio_Augusto_Cancado_Trindade.pdf

${ }_{9}^{9}$ A. CANÇADO TRINDADE, "La ampliación del contenido material del ius cogens", curso derecho internacional 2007,

http://www.oas.org/es/sla/ddi/docs/publicaciones_digital_XXXIV_curso_derecho_inter nacional_2007_Antonio_Augusto_Cancado_Trindade.pdf

10 M. B. REDONDO, "Tutela Preventiva en el paradigma del Juez Humanista Integrativista", Disertación en II Encuentro de la Doctrina Procesal, Preparatorias del IV Encuentro anual de la FAEP y preparatorias del XXVIII Congreso Nacional de Derecho Procesal, Corrientes, marzo de 2015. 
Como así también se vuelve ineludible promover una serie de políticas públicas coordinadas que permitan encontrar la protección y libertad necesarias a todos los seres humanos para poder gozar de sus derechos sin impedimentos.

Es así que la problemática de la violencia de género se vuelve eco en todos los sistemas jurídicos del mundo, por cuanto, los índices de violencia contra la mujer aumentan en vez de disminuir, provocando que la mujer ingrese en la categoría de persona en condición de vulnerabilidad.

De este modo, la mujer que ha sido violentada, no sólo encuentra respuestas deficientes para acceder a la justicia, sino también encuentra restricciones por parte del sistema de protección de normas como por el retraso de las políticas públicas necesarias en comparación con el aumento de los índices de violencia.

Si ut supra afirmábamos que el Estado Democrático de Derecho actual debía asentar sus bases en el respeto de los derechos fundamentales, pero a su vez se observa que las mujeres no sólo sufren violencia por el sólo hecho de ser mujer, sino que además no encuentran las herramientas necesarias para proteger su vida, es necesario replantearse desde los poderes del Estado los pasos a seguir de forma conjunta y realizar un seguimiento para determinar si se está avanzando en ello o no.

Como operadores del derecho instruidos en la conciencia de educación de la población de los Derechos Humanos en nuestro deber aportar investigaciones que pongan de relieve la situación actual, para ser tomadas por los gobiernos de los Estados y de este modo diseñar un plan de acción sostenido en el tiempo y que responda con eficacia a la problemática que nos aqueja a todos como sociedad.

\section{2.- LA TEORÍA NEOCONSTITUCIONAL COMO EL NUEVO PARADIGMA DE LOS SISTEMAS JURÍDICOS DEL MUNDO BASADOS EN LOS DERECHOS HUMANOS}

"Gracias a este embrión de constitución del mundo que está formado por la Carta de la ONU y por las declaraciones, convenciones y pactos internacionales sobre derechos humanos, también la soberanía estatal externa ha sido jurídicamente limitada, por la sujeción de los Estados al imperativo de la paz y a la garantía de los derechos humanos establecidos en esas cartas internacionales" ${ }^{\prime 11}$.

Tal como exponíamos en párrafos previos, la toma de conciencia de la existencia de un catálogo de derechos fundamentales por parte de

11 L. FERRAJOLI, "Sobre los Derechos Fundamentales", Cuestiones Constitucionales Revista Mexicana de Derecho Constitucional., julio-diciembre 2006. 
los Estados y la internalización de los mismos a sus ordenamientos jurídicos trajo como consecuencia el cambio en la concepción de lo que se entiende por Derecho.

Esto cobra especial relevancia por cuanto las normas contenidas en los sistemas jurídicos serán válidas en tanto y en cuanto respeten el contenido de los Derechos Humanos.

De este modo nos preguntamos ¿qué se entiende por derecho actualmente?, y así contestamos que se entiende por tal a la esfera jurídica que comprende a las normas de derecho nacional e internacional de Derechos Humanos, sus principios y los valores superiores que se pretenden proteger.

El marco teórico que entendemos explica este fenómeno de mundialización de los Derechos Humanos es la Teoría Neoconstitucional, considerando que esta teoría se avoca a la expansión de las fuentes del derecho, y pretende explicar la integración del Derecho internacional de los Derechos Humanos en el orden interno de los diversos estados.

Pero no sólo ello, sino que también el Neoconstitucionalismo pretende promover soluciones legislativas, ejecutivas y judiciales que logren una tutela real de los Derechos Humanos, para acortar la brecha entre el ser y el deber ser.

Sin lugar a dudas estamos en una nueva era, en un cambio revolucionario, en donde lo que antes era impensado, como aceptar la apertura semántica de determinados conceptos de derecho e ir significándolos conforme al caso concreto, poniendo en jaque la seguridad jurídica para atender al principio pro homine, hoy necesita de un marco teórico que responda a estos nuevos lineamientos.

Por lo tanto, la teoría jurídica que mejor explica la reformulación de las fuentes del Derecho como consecuencia de la internalización de los Derechos Humanos y la consiguiente búsqueda de mecanismos que los garanticen, como así también la cuestión relativa a la interpretación de los derechos y principios en la decisión judicial y el diseño de políticas públicas efectivas que respeten los derechos fundamentales es la Teoría Neoconstitucional.

Así podemos decir que entendemos por Neoconstitucionalismo a una nueva teoría del derecho, con particularidades propias que responden a la internalización del derecho internacional de los Derechos Humanos, y las consecuencias que ello apareja en las fuentes del derecho, y que no sólo se ocupa de la consagración derechos y de brindar contenidos conceptuales mínimos, sino también en positivizar los mecanismos de efectivización.

Al ser una teoría relativamente nueva nos encontramos con un concepto polisémico del derecho, ya que dentro del mismo se enrolan diversas corrientes con afinidades y diferencias, por lo que la doctrina 
acuerda en hablar de neoconstitucionalismos, haciendo énfasis en el modo plural.

Algunos autores identifican esta teoría como una segunda parte de la teoría constitucional, y en base a ello han dicho que: "Es como una nueva fase en el marco del proceso histórico del constitucionalismo europeo que tuvo comienzo a fines del siglo XVIII, con características propias y diferenciales respecto a las etapas anteriores. De ahí el nombre de neoconstitucionalismo"12.

Sin embargo creemos que al hablar de Neoconstitucionalismo no hacemos referencia simplemente a un proceso de constitucionalización de derechos, sino más bien a un cambio mucho más profundo, que nos viene dado desde afuera (orden público internacional) hacia adentro del sistema jurídico.

Que nos irrumpe con reglas y principios muchos de ellos no sistematizados, pero que se reconocen como válidos y aplicables por la comunidad internacional.

En este sentido reconocidos juristas han expresado que: "si el constitucionalismo tradicionalmente había visto en los procedimientos, en la división y en el equilibrio de competencias, la estrategia de restricción, la perspectiva neoconstitucionalista, por el contrario, insiste en el contenido, en el sentido de las disposiciones de principio y en la enunciación de derechos"13.

Es así que el Neoconstitucionalismo se vuelve una teoría que no sólo se avoca a lo conceptual sino que también cuenta con su faceta práctica, y de ese modo, se vuelve útil a los fines de promover mecanismos que permitan la prevención de la violencia de género, como así también de coordinar un programa sostenido una vez que la violencia contra la mujer ya se haya ejercido.

Habiendo especificado los lineamientos de esta nueva Teoría daremos paso a renglón seguido, al análisis de los instrumentos internacionales de Derechos Humanos que protejan a las mujeres para que puedan llevar una vida libre de toda violencia.

\section{3.- LA VIOLENCIA DE GÉNERO EN LOS DIFERENTES INSTRUMENTOS INTERNACIONALES}

Entre los Tratados Internacionales de protección específica a la mujer encontramos la Convención sobre la Eliminación de todas las

12 S. ALFONSO, "Neoconstitucionalismo", Anales de la Academia Nacional de Ciencias Morales y Políticas. Sesión Privada del Instituto de Política Constitucional, Abril de 2008, p1.

13 S. POZZOLO, "Enciclopedia de Filosofía y teoría del derecho", Biblioteca Jurídica UNAM., p. 367. 
Formas de Discriminación contra la Mujer (CETFDCM) y su Protocolo facultativo, y la Convención Interamericana para Prevenir, Sancionar y Erradicar la Violencia contra la Mujer, conocida también como Convención de Belem do Para.

En líneas generales dichos instrumentos internacionales instituyen la obligación de los Estados de consagrar la igualdad de género en su legislación nacional, derogar todas las disposiciones discriminatorias en sus leyes, y promover nuevas disposiciones para proteger a la mujer contra la discriminación.

Asimismo, las instituciones públicas deben adaptarse para garantizar a las mujeres una protección eficaz contra la discriminación, y adoptar medidas para eliminar todas las formas de discriminación contra la mujer practicada por personas, organizaciones y empresas.

A lo largo de estos años, se ha ampliado la protección no solo para reforzar la igualdad entre hombres y mujeres, sino también para los casos en que el simple hecho de ser mujer, pueda ser una causa de violencia en sus diversas manifestaciones.

En este sentido se ha dicho que los tratados internacionales "son instrumentos vivos que merecen actualizarse y cumplirse en el devenir diario de miles de hombres y mujeres de nuestros pueblos, que aspiran de sus países una protección amplia, efectiva, concreta, que les permita cumplir sueños y proyectos, condiciones para llevar adelante una vida digna"14.

Con lo cual ampliar las fronteras del concepto de violencia de género hacia nuevos supuestos se vuelve una condición necesaria para que el contenido de los instrumentos internacionales no se vuelva letra muerta.

Tomar conocimiento de qué es la violencia de género, dónde puede sufrirse, qué medidas tomar en caso de que ocurra, como así también los derechos que se tienen y lugares de asistencia, se constituyen en ejes necesarios para educar desde la prevención, pero también colaboran como una guía para cuando esos hechos se producen efectivamente.

Recientemente se ha sancionado la Convención Interamericana para la protección de los Derechos Humanos de los adultos mayores, donde se busca tutelar, entre otras cuestiones, la posible vulneración que pueda sufrir una mujer de más de 60 años, incluyendo tanto la discriminación como la violencia por el hecho de ser mujer, sumado a su edad.

En su Preámbulo destaca en cuanto a la violencia y a la discriminación que: "la persona mayor tiene los mismos derechos

\footnotetext{
${ }^{14}$ M. TRUCCO, Convención Americana sobre Derechos Humanos: Pacto de San José de Costa Rica, Editorial Juris, Rosario, 2017.
}

Universitas, 2018, $\mathrm{N}^{\circ} 28 / \mathrm{pp} .38-58$ 
humanos y libertades fundamentales que otras personas, y que estos derechos, incluido el de no verse sometida a discriminación fundada en la edad ni a ningún tipo de violencia, dimanan de la dignidad y la igualdad que son inherentes a todo ser humano"15.

En este sentido el artículo 2 define al maltrato, quedando así contemplada la violencia:

"Maltrato: Acción u omisión, única o repetida, contra una persona mayor que produce daño a su integridad física, psíquica y moral y que vulnera el goce o ejercicio de sus derechos humanos y libertades fundamentales, independientemente de que ocurra en una relación de confianza"16.

Finalmente el artículo 9 establece lo siguiente:

"Derecho a la seguridad y a una vida sin ningún tipo de violencia: La persona mayor tiene derecho a la seguridad y a una vida sin ningún tipo de violencia, a recibir un trato digno y a ser respetada y valorada, independientemente de la raza, el color, el sexo, el idioma, la cultura, la religión, la opinión política o de otra índole, el origen social, nacional, étnico, indígena e identidad cultural, la posición socio-económica, discapacidad, la orientación sexual, el género, la identidad de género, su contribución económica o cualquier otra condición.

La persona mayor tiene derecho a vivir una vida sin ningún tipo de violencia y maltrato.

Para los efectos de esta Convención, se entenderá por violencia contra la persona mayor cualquier acción o conducta que cause muerte, daño o sufrimiento físico, sexual o psicológico a la persona mayor, tanto en el ámbito público como en el privado. Se entenderá que la definición de violencia contra la persona mayor comprende, entre otros, distintos tipos de abuso, incluso el financiero y patrimonial, y maltrato físico, sexual, psicológico, explotación laboral, la expulsión de su comunidad y toda forma de abandono o negligencia que tenga lugar dentro o fuera del ámbito familiar o unidad doméstica o que sea perpetrado o tolerado por el Estado o sus agentes dondequiera que ocurra"17.

Dentro de la normativa vigente internacional también se encuentra el Protocolo para Prevenir, Reprimir y Sancionar la Trata de Personas Especialmente Mujeres y Niños, que complementa la Convención de las Naciones Unidas contra la Delincuencia Organizada Transnacional, la Convención sobre los Derechos de las Personas con Discapacidad y su protocolo facultativo, la Convención sobre los Derechos de los Niños y el

15 Convención Interamericana para la protección de los Derechos Humanos de los adultos mayores, preámbulo.

16 Convención Interamericana para la protección de los Derechos Humanos de los adultos mayores, artículo 2.

17 Convención Interamericana para la protección de los Derechos Humanos de los adultos mayores, artículo 9. 
Protocolo Opcional sobre la Venta de Niños, la Prostitución Infantil y la Pornografía Infantil.

Cabe destacar el aporte que brinda la Ley Nacional Argentina No 26.485 la cual esboza una conceptualización de los distintos tipos de violencia a saber:

"1.- Física: La que se emplea contra el cuerpo de la mujer produciendo dolor, daño o riesgo de producirlo y cualquier otra forma de maltrato agresión que afecte su integridad física.

2.- Psicológica: La que causa daño emocional y disminución de la autoestima o perjudica y perturba el pleno desarrollo personal o que busca degradar o controlar sus acciones, comportamientos, creencias y decisiones, mediante amenaza, acoso, hostigamiento, restricción, humillación, deshonra, descrédito, manipulación aislamiento. Incluye también la culpabilización, vigilancia constante, exigencia de obediencia sumisión, coerción verbal, persecución, insulto, indiferencia, abandono, celos excesivos, chantaje, ridiculización, explotación y limitación del derecho de circulación o cualquier otro medio que cause perjuicio a su salud psicológica y a la autodeterminación.

3.- Sexual: Cualquier acción que implique la vulneración en todas sus formas, con o sin genital, del derecho de la mujer de decidir voluntariamente acerca de su vida sexual o reproductiva a través de amenazas, coerción, uso de la fuerza o intimidación, incluyendo la violación dentro del matrimonio o de otras relaciones vinculares o de parentesco, exista o no convivencia, así como la prostitución forzada, explotación, esclavitud, acoso, abuso sexual y trata de mujeres.

4.- Económica y patrimonial: La que se dirige a ocasionar un menoscabo en los recursos económicos o patrimoniales de la mujer, a través de: bienes;

a) La perturbación de la posesión, tenencia o propiedad de sus

b) La pérdida, sustracción, destrucción, retención o distracción indebida de objetos, instrumentos de trabajo, documentos personales, bienes, valores y derechos patrimoniales;

c) La limitación de los recursos económicos destinados a satisfacer sus necesidades o privación de los medios indispensables para vivir una vida digna;

d) La limitación o control de sus ingresos, así como la percepción de un salario menor por igual tarea, dentro de un mismo lugar de trabajo.

5.- Simbólica: La que a través de patrones estereotipados, mensajes, valores, íconos o signos transmita y reproduzca dominación, 
desigualdad y discriminación en las relaciones sociales, naturalizando la subordinación de la mujer en la sociedad"18.

Además esta Ley señala las modalidades de violencia categorizándolas en:

"Violencia doméstica: aquella ejercida contra las mujeres por un integrante del grupo familiar, independientemente del espacio físico donde ésta ocurra, que dañe la dignidad, el bienestar, la integridad física, psicológica, sexual, económica o patrimonial, la libertad, comprendiendo la libertad reproductiva y el derecho al pleno desarrollo de las mujeres. Se entiende por grupo familiar el originado en el parentesco sea por consanguinidad o por afinidad, el matrimonio, las uniones de hecho y las parejas o noviazgos. Incluye las relaciones vigentes o finalizadas, no siendo requisito la convivencia;

Violencia institucional: aquella realizada por las/los funcionarias/os, profesionales, personal y agentes pertenecientes a cualquier órgano, ente 0 institución pública, que tenga como fin retardar, obstaculizar o impedir que las mujeres tengan acceso a las políticas públicas y ejerzan los derechos previstos en esta ley. Quedan comprendidas, además, las que se ejercen en los partidos políticos, sindicatos, organizaciones empresariales, deportivas y de la sociedad civil;

Violencia Laboral: aquella que discrimina a las mujeres en los ámbitos de trabajo públicos o privados y que obstaculiza su acceso al empleo, contratación, ascenso, estabilidad o permanencia en el mismo, exigiendo requisitos sobre estado civil, maternidad, edad, apariencia física o la realización de test de embarazo. Constituye también violencia contra las mujeres en el ámbito laboral quebrantar el derecho de igual remuneración por igual tarea o función. Asimismo, incluye el hostigamiento psicológico en forma sistemática sobre una determinada trabajadora con el fin de lograr su exclusión laboral;

Violencia contra la libertad reproductiva: aquella que vulnere el derecho de las mujeres a decidir libre y responsablemente el número de embarazos o el intervalo entre los nacimientos, de conformidad con la Ley 25.673 de Creación del Programa Nacional de Salud Sexual y Procreación Responsable;

Violencia obstétrica: aquella que ejerce el personal de salud sobre el cuerpo y los procesos reproductivos de las mujeres, expresada en un trato deshumanizado, un abuso de medicalización y patologización de los procesos naturales, de conformidad con la Ley 25.929.

18 Ley Nacional Argentina No 26.485 de Protección integral para prevenir, sancionar y erradicar la violencia contra las mujeres en los ámbitos en que desarrollen sus relaciones interpersonales, Abril 1, 2009. B.O. 
Violencia mediática: aquella publicación o difusión de mensajes e imágenes estereotipados a través de cualquier medio masivo de comunicación, que de manera directa o indirecta promueva la explotación de mujeres o sus imágenes, injurie, difame, discrimine, deshonre, humille o atente contra la dignidad de las mujeres, como así también la utilización de mujeres, adolescentes y niñas en mensajes e imágenes pornográficas, legitimando la desigualdad de trato o construya patrones socioculturales reproductores de la desigualdad o generadores de violencia contra las mujeres"19.

De este modo la especificidad de la ley de las diversas modalidades de la violencia contra la mujer se constituyen en un gran paso por su amplitud que permiten encuadrar los diferentes casos que se puedan presentar.

Asimismo, es una importante herramienta que los magistrados poseen cuando deben entender en estos casos, ya que se brinda claridad de los supuestos con la técnica legislativa sobre la cual podrán aquéllos fundamentar sus sentencias.

\section{4.- PERSPECTIVAS De LA VIOLENCIA DE géNeRO EN LAS 100 REGLAS DE BRASILIA SOBRE ACCESO A LA JUSTICIA DE LAS PERSONAS EN CONDICIÓN DE VULNERABILIDAD}

"Los derechos fundamentales, como enseña la experiencia, no caen nunca del cielo, sino que llegan a afirmarse cuando se hace irresistible la presión de quienes han quedado excluidos ante las puertas de los incluidos"20.

Las 100 Reglas de Brasilia sobre Acceso a la Justicia de las personas en condición de vulnerabilidad se constituyeron en la Asamblea Plenaria de la Cumbre Judicial Iberoamericana XIV en el año 2008, ellas conforman un conjunto de directrices dirigidas a determinados grupos de personas que comparten características comunes y que deben saltear más obstáculos que el resto de los ciudadanos para acceder a la defensa de sus derechos.

Es así que "Esa porción de la población que por diferentes motivos se encuentra excluida necesita una tutela diferenciada que merme esta imposibilidad de acceso y que por lo tanto le facilite el acceso al hall de la justicia"21.

19 Ley Nacional Argentina No 26.485 de Protección integral para prevenir, sancionar y erradicar la violencia contra las mujeres en los ámbitos en que desarrollen sus relaciones interpersonales. Abril 1, 2009. B.0.

20 L. FERRAJOLI, Derechos y Garantías, Editorial Trotta, Madrid, 2010.

21 M.B. REDONDO, 100 Reglas de Brasilia sobre el acceso a la justicia de las personas en condición de vulnerabilidad .Comentadas. Concordadas con C.P.C.C.S.F. Leyes 
Por lo tanto, estas Reglas se constituyen con el objeto de brindar una protección especial a aquellas personas que se definen como en una condición de vulnerabilidad.

Significando con ello lo siguiente: "un sujeto en condición de vulnerabilidad es aquel que debido a una cualidad intrínseca de su persona encuentra una restricción mayor que la del resto de la población para defender sus derechos, ya sea al momento de la apertura de la instancia judicial como durante la tramitación del juicio, y que por lo tanto, obliga a los operadores de justicia a aplicar las reglas del proceso de una manera activa, para que al entrar en contacto con la justicia la persona no sufra una doble vulnerabilidad, menoscabando derechos fundamentales y causando un daño irreparable"22.

Es decir, se enumeran de un modo no taxativo, a determinados grupos de personas, los cuales pueden encontrarse en una situación diferencial a causa por ejemplo de la pobreza, de la migración, de la edad ya sea en el caso de niñas, niños y adolescentes, como de mayores adultos, y dentro de esta enunciación se contempla a las mujeres víctimas de violencia a causa del género.

Las 100 Reglas definen la violencia en la Regla $n^{\circ} 19$ estableciendo que:

"Se considera violencia contra la mujer cualquier acción o conducta, basada en su género, que cause muerte, daño o sufrimiento físico, sexual o psicológico a la mujer, tanto en el ámbito público como en el privado, mediante el empleo de la violencia física o psíquica"23.

Esta Regla brinda un concepto amplio de violencia al explicitar "toda acción o conducta..." con lo cual podemos decir, que también quedaría incluida la discriminación contra la mujer por el mero hecho de ser mujer, y en este sentido la Regla 18 establece que:

"Se entiende por discriminación contra la mujer toda distinción, exclusión o restricción basada en el sexo que tenga por objeto o resultado menoscabar o anular el reconocimiento, goce o ejercicio por la mujer, independientemente de su estado civil, sobre la base de la igualdad del hombre y la mujer, de los derechos humanos y las libertades fundamentales en las esferas política, económica, social, cultural y civil o en cualquier otra esfera"24.

complementarias. Acordadas C.S.J.S.F. Jurisprudencia provincial, nacional y de la C.I.D.H. Derecho comparado, Editorial Juris, Rosario, 2015.

22 M. B. REDONDO, "Human Rights and Access to Justice, one Neoconstitutional look", Revista Electrónica Iberoamericana, Julio-Diciembre de 2015, p.99.

23100 Reglas de Brasilia sobre el acceso a la justicia de las personas en condición de vulnerabilidad. Regla 19. Marzo 4, 2008.

24100 Reglas de Brasilia sobre el acceso a la justicia de las personas en condición de vulnerabilidad. Regla 18. Marzo 4, 2008.

Universitas, 2018, $\mathrm{N}^{\circ} 28 /$ pp. 38-58 
De este modo podemos decir que "víctima de violencia de género, es toda aquella persona que padece una agresión física, sexual, verbal, psicológica, o económica, en cualquier ámbito donde desarrolle su vida, ya sea en lo público como en lo privado, a la que se le provoca un daño o sufrimiento ocasionalmente o reiteradamente, y que puede llevarla a la muerte" 25 .

Es menester tener en cuenta que no es necesario el ejercicio de violencia sostenido en el tiempo como requisito sine qua non para que ingrese dentro del concepto de violencia de género, bastará solo un acto de agresión contra la mujer a causa del género para quedar encuadrado dentro de esta normativa más tuitiva y de los instrumentos internacionales.

El aporte fundamental que nos traen las 100 Reglas de Brasilia a la normativa internacional existente, son las pautas que deben adoptar los operadores de todo sistema de justicia, en aras de brindar una protección adecuada para que la vulnerabilidad en la que se encuentra la mujer violentada no constituya un obstáculo para defender sus derechos correctamente.

El trato humanizado que debe darse a toda persona que interviene en un proceso judicial se acentuará aun más teniendo en consideración las necesidades específicas de la víctima, como por ejemplo el estar acompañada en determinados actos procesales por personas de su círculo de confianza, e incluso los Magistrados deberán estarse a determinadas pautas de protección tal es el caso de mujeres menores de edad que pueden sufrir más de una vulnerabilidad, en este caso al ser menor y el ser mujer, como ejemplo de ello encontramos la Regla 80 que establece que las actuaciones judiciales podrán no sean públicas, y la Regla 78 prevé la utilización de términos claros y sencillos en las actuaciones en las que deben intervenir para que puedan ser fácilmente comprensibles por ellos, y en cuanto a la violencia de género en el seno familiar las Reglas 75 y 76 hacen un llamado de atención al derecho de ser oído, y "al resguardo psíquico de aquellas personas en condición de vulnerabilidad que han sido dañadas de manera constante por haber sido víctimas continuas de hechos delictivos" 26 .

De este modo se complementan las diferentes Convenciones con las pautas fijadas por las 100 Reglas de Brasilia para lograr una mayor

25 M. B. REDONDO, "Violencia de género: Mujeres como sujetos vulnerables", Revista Al día Argentina, Octubre de 2017.

${ }^{26}$ M.B. REDONDO, 100 Reglas de Brasilia sobre el acceso a la justicia de las personas en condición de vulnerabilidad .Comentadas. Concordadas con C.P.C.C.S.F. Leyes complementarias. Acordadas C.S.J.S.F. Jurisprudencia provincial, nacional y de la C.I.D.H. Derecho comparado, Editorial Juris, Rosario, 2015.

Universitas, 2018, $\mathrm{N}^{\circ} 28 /$ pp. 38-58 
María Belén Redondo - Perspectivas de la violencia de género en la era de la Teoría Neoconstitucional...

eficiencia en la tutela judicial efectiva de las mujeres víctimas de violencia de género.

\section{5.- DOS CASOS EMBLEMÁTICOS SOBRE VIOLENCIA DE GÉNERO QUE CRISTALIZAN LA EFECTIVIDAD DE LA NORMATIVA EN ARGENTINA}

"La no violencia guía a la ética superior, la cuál es la meta de toda evolución. Hasta que dejemos de dañar otros seres vivos, seguimos siendo salvajes". (Thomas. A. Edison)

En los últimos años en Argentina se vio incrementado el índice de violencia de género contra la mujer, revelando fuentes periodísticas ${ }^{27}$ que ocurre un femicidio cada 18 horas, basándose en un informe realizado por el Instituto de Políticas de Género Wanda Taddei en el año 2017, a causa de ello, la jurisprudencia fue resolviendo los diversos casos que se presentaron a sus estrados sentando así las nuevas bases que se corresponden con lo dispuesto para la violencia contra la mujer en el Derecho internacional de los Derechos Humanos.

En el primer caso, una mujer denunció en reiteradas oportunidades la violencia que ejercía su ex marido sobre ella, obteniendo respuestas insatisfactorias por parte de la policía como del poder judicial provincial.

Lo que dio lugar finalmente a su asesinato y al de su hijo menor de edad en manos de su ex marido.

Los padres de la mujer iniciaron una demanda contra el Estado provincial reclamando la indemnización correspondiente por los daños materiales y morales sufridos, la cual en primera instancia fue rechazada, y llega así a la Cámara de Apelaciones en la cual el fallo da un giro inesperado sentado así las bases de una nueva jurisprudencia que lleva adelante el debido control de convencionalidad.

En este sentido la Cámara ha dicho que: "La Corte Interamericana ya había considerado en otros precedentes que la atribución de responsabilidad del Estado por actos de particulares puede darse cuando el Estado incumple, por acción u omisión de sus agentes, con esta función de protección, pero sólo en aquellas circunstancias particulares en que se considere que los agentes estatales cumplían una posición de garantes con relación a la acción de los particulares; tomando insisto como base la doctrina del riesgo previsible y evitable. No se trata de atribuir responsabilidad estatal frente a cualquier violación de derechos

27j. ROFFO, Cada 18 horas un chico se queda sin madre en el país por los femicidios. Clarín. Julio, 23, 2017.

https://www.clarin.com/sociedad/18-horas-chico-queda-madre-pais-

femicidios_0_S1WS-TGUW.html

Universitas, 2018, $\mathrm{N}^{\circ} 28 /$ pp. 38-58

ISSN 1698-7950 / doi: https://doi.org/10.20318/universitas.2018.4310 
humanos cometida entre particulares. El deber del Estado de adoptar medidas de prevención y protección está condicionado, según la Corte, por el conocimiento de una situación de riesgo real e inmediato para un individuo o grupo de individuos determinado y por la posibilidad razonable de prevenir y evitar ese riesgo" 28 .

Así también fundamenta su sentencia en el análisis que realizó la Corte Interamericana de Derechos Humanos en el caso "Campo Algodonero" 29 en el que el Máximo Tribunal interamericano dijo que: "Los Estados deben adoptar medidas integrales para cumplir con debida diligencia en casos de violencia contra las mujeres. En particular, deben contar con un adecuado marco jurídico de protección, con una aplicación efectiva del mismo, con políticas de prevención y prácticas que permitan actuar de una manera eficaz ante las denuncias. La estrategia de prevención debe ser integral, es decir, debe prevenir los factores de riesgo y a la vez fortalecer las instituciones para que puedan proporcionar una respuesta efectiva de los casos de violencia contra la mujer. Asimismo los Estados deben adoptar medidas preventivas en casos específicos en los que es evidente que determinadas mujeres y niñas pueden ser víctimas de violencia. Todo esto debe tomar en cuenta que en casos de violencia contra la mujer, los Estados tiene, además de las obligaciones genéricas contenidas en la convención americana, una obligación reforzada a partir de la convención de Belém do Para." (CIDH, Caso Campo Algodonero, párrafo 258)"30.

Con lo cual finalmente la Cámara resuelve que "la conducta omisiva del Estado que venimos referenciando, debe calificarse como un "elemento facilitador" del lamentable suceso ocurrido -ingresando de esa manera como una concausa- ; por lo que corresponde endilgarle al Estado Provincial el cincuenta por ciento de la responsabilidad de los hechos base de esta acción"31.

En el segundo caso una mujer presenta una denuncia en la Defensoría del Pueblo de la Nación contra la neonatóloga, el obstetra, la obra social prepaga y la clínica en la que nació la hija de la mujer víctima de violencia obstétrica.

${ }^{28}$ Cámara de Apelaciones en lo Civil y Comercial de la ciudad de Córdoba .Sentencia n 122. (Dra. Claudia E. Zalazar \&, Dr. Rafael Aranda \&, Dr. Joaquin Ferrer; julio 23 de 2014).

${ }^{29}$ Ct. I.D.H. González y otras ("campo algodonero") vs. México, 2009.

${ }^{30}$ Cámara de Apelaciones en lo Civil y Comercial de la ciudad de Córdoba. Sentencia n 122. (Dra. Claudia E. Zalazar \&, Dr. Rafael Aranda \&, Dr. Joaquin Ferrer; julio 23 de 2014).

${ }^{31}$ Cámara de Apelaciones en lo Civil y Comercial de la ciudad de Córdoba. Sentencia $\mathrm{n}^{\circ}$ 122. (Dra. Claudia E. Zalazar \&, Dr. Rafael Aranda \&, Dr. Joaquin Ferrer; julio 23 de 2014).

Universitas, 2018, $\mathrm{N}^{\circ} 28 /$ pp. 38-58

ISSN 1698-7950 / doi: https://doi.org/10.20318/universitas.2018.4310 
Dicha defensoría luego de una auditoría realizada por la Superintendencia de Servicios de Salud (SSSALUD) corrobora la existencia de violencia obstétrica denunciada.

La mujer previo a dar a luz había presentado un "plan de parto" donde solicitó por escrito que durante el mismo no hubiera gente de más, que las luces se encontraran bajas y que, con excepción de que la beba desarrollara alguna complicación durante el mismo, la debían apoyar en su pecho rápidamente, sin bañarla y sin pincharla, para respetar lo que se conoce como "la hora sagrada", sobre la cual UNICEF $^{32}$ ha emitido informes avalando la importancia del contacto de la madre con su bebé durante los primeros 60 a 90 minutos posteriores al parto.

Sin embargo, la madre vivió diversas situaciones de violencia durante el parto incumpliendo el personal el plan de parto presentado ante la clínica, que le causaron padecimientos que la invadieron no sólo desde un aspecto físico sino también psicológico.

Actualmente se encuentra en curso una demanda por daño moral ante aquellas mismas personas que habían sido denunciadas en la Defensoría Nacional.

A causa de este caso la SSSALUD realizó las siguientes sugerencias a la Clínica en cuestión:

". Se recomienda seguir con la Educación Profesional Continua de todos los integrantes del equipo de salud y administrativo, institucional y externos, ajustándose a la normativa vigente: Leyes 26.485 y 25.929 , en Derechos Humanos, Derechos de las y los Pacientes y Parto Respetado, con el fin de garantizar un tratamiento respetuoso del nacimiento en los términos que establece la Ley 25.929.

Exhibir, en forma permanente y accesible, en las áreas comunes y en las que intervienen en el proceso de parto y el puerperio, materiales vinculados a los Derechos de las Mujeres" 33 .

De lo expuesto se desprende que tanto el caso presentado en sede judicial como el que se inició a través de la denuncia en la Defensoría del Pueblo de la Nación y que luego dio lugar a la demanda por daño

32U.N. UNICEF. Determinantes sociales y ambientales para el desarrollo de los niños, niñas desde el período del embarazo hasta los 5 años: bases para un diálogo deliberativo, Abril, 2015,

https://www.unicef.org/argentina/spanish/SALUD_PBPrimeraInfancia_web(1).pdf

33 Defensor del Pueblo de la Nación Argentina. Ante una grave denuncia de Violencia Obstétrica, la Defensoría del Pueblo exigió a una clínica que garantice la práctica de parto humanizado, Gacetilla, Enero 18, 2016, https://blogdeprensa.com.ar/gacetillas/1352-ante-una-grave-denuncia-de-violenciaobstetrica-la-defensoria-del-pueblo-exigio-a-una-clinica-que-garantice-la-practica-departo-humanizado

Universitas, 2018, $\mathrm{N}^{\circ} 28 /$ pp. 38-58

ISSN 1698-7950 / doi: https://doi.org/10.20318/universitas.2018.4310 
moral, avanzan sobre los diversos conceptos de violencia contra la mujer, permitiendo trazar lineamientos propios de cada modalidad.

Los avances en su especificidad abre también el abanico de posibilidades en cuanto al diseño de políticas públicas para educar en la prevención a la sociedad, tal es el ejemplo del Proyecto titulado "Manual de prevención de Violencia de Género: Ni una Menos"34 para los colegios secundarios, presentado al Concejo Municipal de la ciudad de Rosario por una Profesora y Funcionaria del Poder Judicial santafecino, que pretende promover una conciencia educativa a través del debate ciudadano desde la temprana edad.

\section{6.- CONCLUSIÓN}

A modo de conclusión podemos señalar que frente a los cambios que se dan por la mundialización de los Derechos Humanos y el fenómeno que se produce en cuanto a la recepción de tales derechos fundamentales en los diferentes sistemas jurídicos de los Estados, es menester coordinar acciones entre los agentes nacionales e internacionales, como así también readecuar las instituciones a los fines de dar cumplimiento con lo establecido por los instrumentos internacionales vigentes.

Dentro de este catálogo de derechos se deben garantizar aquellos vinculados a la no discriminación y no violencia contra la mujer a causa del género.

La misión de los Estados será lograr la integración de los derechos con sus respectivas garantías de modo que las víctimas de violencia encuentren respuestas efectivas por parte del Estado a través de sus agentes.

En caso contrario, y tal como hemos visto, los Estados podrían ser condenados como responsables por el incumplimiento de sus obligaciones y a resarcir los daños provocados.

A lo que agregamos la inquietud en cuanto también podría incurrir el Estado en responsabilidad internacional por el incumplimiento de sus obligaciones convencionales por cuanto no cumplen con la adopción de medidas necesarias para erradicar la violencia o la discriminación a causa del género, o las que se implementan resultan evidentemente insuficientes.

34 M. PRIETO, "María Belén Redondo y su manual de prevención sobre la violencia de género", 341 Media. Agosto 2, 2017. http://341media.com.ar/maria-belen-redondo-ysu-manual-de-prevencion-sobre-la-violencia-de-genero/ y en "Presentan manual para concientizar sobre la violencia de género desde las escuelas", Diario La Capital, Sección Región, Julio 31, 2017, http://www.regionlacapital.com/2017/07/presentan-manualpara-concientizar-sobre-la-violencia-de-genero-desde-las-escuelas/

Universitas, 2018, $\mathrm{N}^{\circ} 28 /$ pp. 38-58 
Apostar a que los índices de violencia disminuyan a través de políticas de prevención por ejemplo desde las escuelas a través de manuales explicativos, no sólo de las normas de protección sino también de los centros de denuncia, las modalidades y tipos de violencia, entre otras, permiten crear conciencia desde la adolescencia de esta problemática y estar alertas para solidarizarse con aquellas mujeres que padecen la violencia de género.

\section{7.- BIBLIOGRAFÍA}

100 Reglas de Brasilia sobre el acceso a la justicia de las personas en condición de vulnerabilidad, 2008.

ALTERIO, "Corrientes del constitucionalismo contemporáneo a debate", Anuario de Filosofía y Teoría del Derecho, Mayo 2013, p. 227.

CANÇADO TRINDADE, "La ampliación del contenido material del ius cogens", curso derecho internacional 2007, http://www.oas.org/es/sla/ddi/docs/publicaciones_digital_XXXIV_curso_ derecho_internacional_2007_Antonio_Augusto_Cancado_Trindade.pdf

Cámara de Apelaciones en lo Civil y Comercial de la ciudad de Córdoba. Sentencia n 122. (Dra. Claudia E. Zalazar \&, Dr. Rafael Aranda \&, Dr. Joaquin Ferrer; julio 23 de 2014).

Convención Interamericana para la protección de los Derechos Humanos de los adultos mayores. 2009.

Ct. I.D.H. González y otras ("campo algodonero") vs. México,

Defensor del Pueblo de la Nación Argentina. Ante una grave denuncia de Violencia Obstétrica, la Defensoría del Pueblo exigió a una clínica que garantice la práctica de parto humanizado, Gacetilla, Enero 18, 2016,

https://blogdeprensa.com.ar/gacetillas/1352-ante-una-grave-denunciade-violencia-obstetrica-la-defensoria-del-pueblo-exigio-a-una-clinicaque-garantice-la-practica-de-parto-humanizado

Diario La Capital, "Presentan manual para concientizar sobre la violencia de género en las escuelas" nota a M.B. REDONDO, Sección Región, Julio 31, 2017, http://www.regionlacapital.com/2017/07/presentan-manual-paraconcientizar-sobre-la-violencia-de-genero-desde-las-escuelas/

F. QUISPE REMÓN, "Ius cogens en el Sistema Interamericano: su relación en el debido proceso", Revista de Derecho, Julio-Diciembre 2010.

H. RAMÍREZ GARCÍA y OTROS, Derechos Humanos, Editorial Oxford University Press, Editorial Oxford University Press, México, 2011. 
2010.

L. FERRAJOLI, Derechos y Garantías, Editorial Trotta, Madrid,

Ley Nacional Argentina No 26.485 de Protección integral para prevenir, sancionar y erradicar la violencia contra las mujeres en los ámbitos en que desarrollen sus relaciones interpersonales, Abril 1, 2009. B.O.

M. B. REDONDO, "Human Rights and Access to Justice, one Neoconstitutional look", Revista Electrónica Iberoamericana, JulioDiciembre de 2015.

M. B. REDONDO, "Tutela Preventiva en el paradigma del Juez Humanista Integrativista", Disertación en II Encuentro de la Doctrina Procesal, Preparatorias del IV Encuentro anual de la FAEP y preparatorias del XXVIII Congreso Nacional de Derecho Procesal, Corrientes, marzo de 2015.

M. B. REDONDO, "Violencia de género: Mujeres como sujetos vulnerables", Revista Al día Argentina, Octubre de 2017.

M. PRIETO, "María Belén Redondo y su manual de prevención sobre la violencia de género", 341 Media. Agosto 2, 2017.

http://341media.com.ar/maria-belen-redondo-y-su-manual-deprevencion-sobre-la-violencia-de-genero/ y en "Presentan manual para concientizar sobre la violencia de género desde las escuelas",

M. TRUCCO, Convención Americana sobre Derechos Humanos: Pacto de San José de Costa Rica, Editorial Juris, Rosario, 2017.

M.B. REDONDO, 100 Reglas de Brasilia sobre el acceso a la justicia de las personas en condición de vulnerabilidad .Comentadas. Concordadas con C.P.C.C.S.F. Leyes complementarias. Acordadas C.S.J.S.F. Jurisprudencia provincial, nacional y de la C.I.D.H. Derecho comparado, Editorial Juris, Rosario, 2015.

S. ALFONSO, "Neoconstitucionalismo", Anales de la Academia Nacional de Ciencias Morales y Políticas. Sesión Privada del Instituto de Política Constitucional, Abril de 2008, p1.

S. POZZOLO, "Enciclopedia de Filosofía y teoría del derecho", Biblioteca Jurídica UNAM., p. 367.

U.N. UNICEF. Determinantes sociales y ambientales para el desarrollo de los niños, niñas desde el período del embarazo hasta los 5 años: bases para un diálogo deliberativo, Abril, 2015, https://www.unicef.org/argentina/spanish/SALUD_PBPrimeraInfancia_w $\mathrm{eb}(1) \cdot \mathrm{pdf}$ 